\title{
Prevalence of HBV Genotypes in South American Immigrants Affected by HBV-Related Chronic Active Hepatitis
}

\author{
Emilio Palumbo, Gaetano Scotto, Giuseppina Faleo, Donatella Concetta Cibelli and Gioacchino Angarano \\ Clinic of Infectious Diseases, University of Foggia; Foggia, Italy
}

\begin{abstract}
This study evaluated the prevalence of $\mathrm{HBV}$ infection in a population of South American immigrants in Italy and to determine in patients with detectable serum HBV-DNA the HBVgenotypes. Between April 2005 and April 2006 a total of 130 South American immigrants were tested for HBsAg. In HBsAg positive patients the biochemical and virological activity of infection and the possible presence of co-infections (HCV, HDV, HIV) were evaluated. In patients with detectable serum HBV DNA, the HBV genotype was determined by INNOLiPA. Among the 130 subjects tested, $14(10.7 \%)$ resulted HBsAg positive. All were men, with a mean age of 22 years (range 19-37) and 12 $(\mathbf{8 5 . 7} \%)$ came from Brazil, while $2(\mathbf{1 4 . 3} \%)$ came from Ecuador. All patients infected by HBV had elevated alanineaminotransferase serum levels (mean level was $127 \mathrm{IU} / \mathrm{L}$, range 74-312) and serum HBV DNA detectable by PCRReal Time (mean level 1,037,652 copies/mL, range 19,876-1,377,648). Genotype distribution was as follow: genotype D, $9(64.2 \%)$, genotype A, $5(35.8 \%)$. All patients infected by genotype D came from Brazil, while among the patients infected by genotype A, three came from Brazil and two from Ecuador. Our study evidences a moderate prevalence of HBV-infection in South American immigrants with the identification of two genotypes, $D$ and A. These genotypes are not the most prevalent in the South America and this is probably the expression of a possible geographical redistribution of $\mathrm{HBV}$ genotypes.
\end{abstract}

Key-Words: HBV genotypes, chronic hepatitis B, immigrants, HBsAg, viral genome.

Hepatitis B virus (HBV) infection is a major health problem and more than 350 million of the world population are chronic carriers of the virus [1,2]. In the world there are some areas characterized by a prevalence of infection $>8 \%$, as the major part of sub-Saharan Africa, the Southeast Asia, some central regions in South America and some European countries, as Albania and Turkey. Actually, Italy is characterized by a low prevalence $(<2 \%)$ [3], but the immigration phenomenon could be determinant tothe introduction in our area of many people infected by HBV with, consequently, an increase of the prevalence. In Italy the immigration flow is characterized by subjects coming from EasternEurope ( 35\% of total immigrants), Africa ( 25\%), South America ( 25\%) and Asia ( 15\%) [4]. The major part of South American subjects comes from Brazil and Colombia (45\% and 35\%, respectively). In Italy, where the prevalence of $\mathrm{HBV}$ infection is $2 \%-8 \%$, the prevalent genotype is D (in fact about $95 \%$ of Italian patients with HBV infection presented this genotype), while in other areas, as Central and South America, other HBV genotypes are prevalent and the migratory flow towards our country could be determinant to the introduction in our area of genotype non-D HBV infections. In fact, HBV genome has been classified in eight genotypes (A to $\mathrm{H}$ ), according to the criterion of $\geq 8 \%$ differences in the complete nucleotide sequence of the viral genome [5-10] HBV genotypes have a characteristic geographic distribution. Genotype A is widely distributed in Northwest Europe, North

Received on 10 January 2007; revised 16 May 2007.

Address for correspondence: Dr. Emilio Palumbro. Clinic of Infectious Diseases, University of Foggia. Via Luigi Pinto, 1,71000. Foggia, Italy. Phone: + 390881 732091. Fax: + 390881 732215. E-mail: emipalu2003@yahoo.it.

The Brazilian Journal of Infectious Diseases 2007;11(3):311-313. (C) 2007 by The Brazilian Journal of Infectious Diseases and Contexto Publishing. All rights reserved.
America and Central Africa, while genotypes $\mathrm{B}$ and $\mathrm{C}$ are present in Asia only; genotype D has been found worldwide with its highest prevalence in Mediterranean area, Middle East and South Asia, particularly in India. Genotype E is found in subSaharan Africa and genotype F in South and Central America. Genotype $\mathrm{G}$ has been found in France and in USA, but recent data point to a Central America or Mexican origin, while the newly discovered genotype $\mathrm{H}$ seems so far to be restricted to the northern part of Latin America [5,8,9].

The aim of this study was to evaluate the prevalence of HBV infection in a population of South American immigrants in Italy and to determine in patients with detectable serum HBV-DNA the HBV genotypes.

\section{Materials and Methods}

Between April 2005 and April 2006, a total of 130 immigrants coming from South America were tested for HBsAg. All subjects received written informed consent. Tested subjects were temporarily guests in a camp for refugees. They were in Italy by a mean period of five months (ranged from 68 days to 10 months) and the majority $(80,61.5 \%)$ came from Brazil, while 23 (17.6\%) subjects from Colombia, 14 (10.7\%) from Peru, 8 (6.1\%) from Chile and 5 (4.1\%) from Ecuador. The mean age of all tested subjects was 21.3 years (range 15-43) and the major part was men (92/130,70.7\%).

In HBsAg positive patients the biochemical and virological activity of infection and the eventual presence of co-infections (HCV, HDV, HIV) were evaluated. In patients with detectable serum HBV-DNA, was determined the HBV genotype.

HBsAg was assayed by commercial immunoassay (Abbott-Auszyme Mc, Abbott Laboratories, North Chicago, IL). Hepatitis B e Antigen (HbeAg) and antibody to HbeAg (anti-HBe) were detected by radioimmunoassay (HbeAg/ antiHBe immunoradiometric DiaSorin, Vercelli, Italy). IgM and IgG anti-HDV were tested with commercially available ELISA 
kits (Abbott Diagnostica, Weisbaden-Delkenheim, Germany). The presence of antibodies to HCV (anti-HCV) was determined with the use of a third-generation enzyme-linked immunosorbent assay (HCV-ELISA, Ortho Diagnostic System, Raritan, NJ, USA) and confirmed by a third-generation recombinant immunoblot assay (RIBA, Ortho Diagnostic Systems, Raritan, NJ, USA). Antibodies to HIV (anti-HIV) were determined by EIA (HIV1/ HIV2, Abbott) and positive results were confirmed by Western Blot. Serum HBV-DNA levels were measured by a commercial PCR-Real Time with a detection limit of 100 copies $/ \mathrm{mL}$. Serum alanine-aminotrasferase (ALT) levels were quantified by ultraviolet enzymatic assay (normal range 0-40 IU/L).

\section{Determination of HBV Genotypes}

Serum of all patients with detectable serum HBV-DNA was stored at $-80^{\circ} \mathrm{C}$ then thawed to determine HBV genotype. For determination of HBV genotypes HBV-DNA was extracted as described by Stuyver et al. [6]. The second step was the nucleic acid amplification of the HBV pol gene domain B and $\mathrm{C}$ by means of the polymerase chain reaction (PCR), for obtaining sequence information pertaining to codons 180, 204 and 207 in the polymerase open reading frame. The extracted DNA was amplified over two rounds of PCR using biotinylated PCR primers. An exact copy of the template was produced after one cycle of denaturation, annealing and extension.

Because the amount of amplification product is generally not sufficient, a nested (second round) PCR was needed. After the two PCR for amplification, HBV genotypes were determined by the INNO-LiPA HBV Genotyping (Innogenetics NV, Gent, Belgium).

\section{Statistical Analysis}

A two-tailed Pearson $\chi^{2}$ test was used to compare categorical data. Statistical significance was taken as $p<0.05$. The software used for the statistical analysis was EPI info version 6 program.

\section{Results}

Among the 130 subjects tested, 14 (10.7\%) resulted HBsAg positive. All were men, with a mean age of 22 years (range 1937 ) and $12(85.7 \%)$ came from Brazil, while $2(14.3 \%)$ came from Ecuador. All patients resulted anti-HBe positive, with IgM anti-core, IgM and IgG anti-HDV negative. No subject presented co-infection with HCV and HIV. Serum bilirubin, albumin and prothrombin time resulted normal in all subjects. All patients infected by HBV had ALT levels elevated above laboratory normal values (mean level was 127 IU/L, range 74312) and serum HBV-DNA detectable by PCR-Real Time (mean level 1.037.652 copies/mL, range 19.876-1.377.648).

Genotype distribution was finally determined in all patients with detectable serum HBV-DNA as follow: genotype D, 9 (64.2\%), genotype A, 5 (35.8\%). No cases of mixed genotype were evidenced. All patients infected by genotype $\mathrm{D}$ came from Brazil, while among the patients infected by genotype A, three came from Brazil and two from Ecuador. The mean ALT levels and serum HBV-DNAlevels were similar among the two different genotype ( $145 \mathrm{IU} / \mathrm{L}$ and 958,870 copies $/ \mathrm{mL}$ for genotype $\mathrm{D} v s$. $139 \mathrm{IU} / \mathrm{L}$ and 902,668 copies $/ \mathrm{mL}$ for genotype $\mathrm{A})(\mathrm{p}=0.9$ for ALT and 0.7 for serum HBV) (Table 1). No patient was aware of his positivity for HBsAg before our screening and in all cases the risk factor for $\mathrm{HBV}$ infection was unknown. All 14 infected patients were in Italy by a mean period of 79 days (range 68116 ) and certainly were infected in their original country.

Table 1. Distribution of HBV genotypes in patients with detectable serum HBV-DNA and correlation between different genotypes with biochemical and virological activity of HBVrelated disease

\begin{tabular}{lcc}
\hline & \multicolumn{2}{c}{ HBV genotypes } \\
\cline { 2 - 3 } & D & A \\
\hline $\begin{array}{l}\text { Patients infected by } \\
\text { different genotypes }\end{array}$ & $9(64.2 \%)$ & $5(35.8 \%)$ \\
Provenience & All Brazil & 3 Brazil \\
Mean ALT (IU/L) & 145 & 2 Ecuador \\
Mean HBV-DNA(copies/mL) & 958,870 & 902,668 \\
\hline
\end{tabular}

Estatistical analysis did not evidence any significative correlation between biochemical and virological activity of the disease and the different HBV genotypes.

\section{Discussion}

Some recent studies have evidenced that in immigrants the prevalent infectious diseases are represented by HIV, tuberculosis and chronic viral hepatitis, more frequently caused by HBV [1115]. People coming from South America represent about $20 \%$ of total immigrants in Italy and they are an important community in our country. The principal aim of this study was to evaluate the prevalence of HBV infection in a population of South American immigrants, in Italy by a mean period of 5 months. We have tested 130 subjects: the major part was from Brazil and it reflects the actual prevalent migratory flow to Italy, prevalently characterized by people coming from Brazil and, less frequently, from Colombia, Chile and Ecuador. Amongst this population, 14 subjects (10.7\%) resulted HBsAg positive and this rate was alike to similar observations presented in Italian and international literature [11,12] No cases of co-infection were observed. All of these subjects presented elevated serum ALT levels and detectable serum HBVDNA in PCR. The data about the elevated ALT levels is surprising, because many studies have evidenced that in immigrant subjects, particularly in sub-Saharan African population, but also in South American people, $\mathrm{HBV}$ infection is characterized by an elevated prevalence (> 8\%), but many infected subjects (a variable rate of $40-65 \%$ in the different studies) not present biochemical activity of diseases $[11,14,15]$. Probably, our data is connected with the low number of infected subjects. An important data concerned the sex of infected patients: all HBsAg positive subjects were men, but this data is probably expression of the difficulty in testing females (only 38/130 of tested subjects were females). 
The second aim of the study was to determine, in patients with virological activity of infection (detectable serum HBV-DNA), the prevalence of HBV genotypes. In Italy, in the autochthon population affected by active chronic $B$ hepatitis, $\mathrm{HBV}$ genotypes are not investigated, because the major part of patients (about 95\%) presents genotype D; however the migratory flow could determine the introduction in our country of patients infected by genotype non-D HBV and for this reason it is important to study the diffusion of different genotypes in the immigrants infected by HBV. In addition, some studies have recently suggested that the HBV genotype is correlated with the clinical features of HBV infection and with the response to antiviral treatments. In fact, with regard to genotypes $\mathrm{B}$ and $\mathrm{C}$, which are prevalent in Asia, genotype $\mathrm{C}$ has been shown to be more frequently found in severe liver disease and in hepatocellular carcinoma and it presents a lower response rate to interferon alfa therapy, while genotype $\mathrm{B}$ is associated with faster $\mathrm{Hbe} \mathrm{Ag} / \mathrm{antiHBe}$ seroconversion [16-20]. During treatment with lamivudine, YMDD variants seem to appear faster in genotype A patients than genotype $\mathrm{D}$ but appear earlier in genotype $\mathrm{D}$ [21].

Therefore these different genotypes, probably characterized by a different natural history and a different response to therapy, could require a different clinical and therapeutic approach as compared to genotype D. In our study the prevalent genotype was D ( 9 cases, $64.2 \%$ ), (50\% of cases), evidenced exclusively in Brazilian patients, while 5 patients resulted infected by genotype A, three coming from Brazil and two from Ecuador. Any patient resulted infected by genotypes F and G, the prevalent in South-America, while patients resulted positive for genotypes characterized by a prevalent diffusion in Northwest Europe, North America and Central Africa (genotype A) and in the Mediterranean area, the Middle East and South Asia (genotype D).

This could demonstrate as the global migratory flow in the world could determine a partial modification of the normal geographic distribution of HBV genotype with the distribution of some genotype in areas where they are not precedently diffused. In fact, South American countries, as Brazil, have also been interested by an important migratory flow, characterized by people coming to Mediterranean area and Northwest Europe, as Italy, with the possible diffusion among the autochthon population of different HBV genotype, as D and A. About the biochemical and virological activity of HBV infection, while the mean ALT levels and HBV-DNA serum levels were similar among the two different genotype.

In conclusion our study evidences a moderate prevalence of HBV infection in South American immigrants, with the identification of two genotypes, D and A. These genotypes are not the most prevalent in the South America and this probably is the expression of a possible geographical redistribution of HBV genotypes.

To investigate the geographical distribution and the clinical, virological and therapeutic response characteristics of HBV genotypes, further studies using a large number of samples should be performed.

\section{References}

1. Chu C.M., Liau Y.F. Natural history of chronic B virus infection: an immunophatological study. J Gastroenterol Hepatol 1997; $12:$ S218-S22.

2. Purcell R.H. The discovery of the hepatitis viruses. Gastroenterology 1993;104:955-63.

3. Fattovich G., Mcintyre G., Thursz M., et al. Hepatitis B virus precore/core variation and interferon therapy. Hepatology 1995; $22: 1355-62$

4. Caritas/Migrantes. Immigrazione Dossier Statistico 2004. Roma: Nuova Anterem, 2004

5 Man-Fung Y., Erwin S., Yasuhito T., et al. Epidemiological study of hepatitis B virus genotypes, core promoter and precore mutations of chronic hepatitis B infection in Hong Kong. J Hepatol 2004;41:119-25.

6. Stuyver L., De Gendt S., Van Geyt C., et al. A new genotype of hepatitis virus: complete genome and phylogenetic relatedness. J Gen Virol 2000;81:67-74.

7. Arauz-Ruiz P., Norder H., Robertson B.H., Magnius L.O. Genotype $\mathrm{H}$ : a new Ameridian genotype of hepatitis B virus revealed in Central America. J Gen Virol 2002;83:2059-73.

8. Senturker Guldas N., Abacioglu Y.H. S-gene sequences and genotype-related restrinction sites in hepatitis B virus carriers in Turkey. Infection 2004;32:344-9.

9. Yalcin K., Degertekin H., Bahcecioglu I.H., et al. Hepatitis B virus prevails in patients with persistently elevated or normal ALT levels in Turkey. Infection 2004;32:24-9.

10. Jia-Horng K., Nan-Hui W., Pei-Jer C., et al. Hepatitis B genotypes and the response to interferon therapy. J Hepatol 2000;33:9981002 .

11. Scotto G., Saracino A., Pempinello R., et al. Epidemiological multicentric study on prevalence of hepatitis in hospitalised immigrants in Italy during 2002;Ann Ig 2005;17:11-8.

12. Lopez-Velez R., Huerga H., Turrientes M.C. Infectious diseases in immigrants from the perspective of a tropical medicine referral unit. Am J Trop Med Hyg 2003;69:115-21.

13. Roberts A., Kemp C. Infectious diseases of refugees and immigrants: hookworm. J Am Acad Nurse Pract 2002;14:194.

14. Ramos J.M., Pastor C., Masia M.M., et al. Health in the immigrant population: prevalence of latent tuberculosis, hepatitis B, hepatitis $\mathrm{C}$, human immunodeficiency virus and syphilis infection. Enferm Infecc Microbiol Clin 2003;21:540-2.

15. Schwanig M. Migration: public health issues (polio, hepatitis C, hepatitis B, tuberculosis, diphteria). Biologicals 1997; $25: 187-93$

16. Hajime S., Osamu Y., Naohiko S., et al. Influence of hepatitis B virus genotype on the progression of chronic type B liver disease. Hepatology 2003;37:19-26.

17. Man-Fung Y., Erwin S., He-Jun Y., et al. Significance of hepatitis $\mathrm{B}$ genotype in acute exacerbation, $\mathrm{Hbe} \mathrm{Ag}$ seroconversion, cirrhosis-related complications, and hepatocellular carcinoma. Hepatology 2003;37:562-7.

18. Lik-Yuen Chan H., Woon-Choi Tsang S., ChooK-Tiew L., et al. Viral genotype and hepatitis B virus DNA levels are correlated with histological liver damage in HbeAg-negative chronic hepatitis B virus infection. Am J Gastrenterol 2002;97:406-12.

19. Xin D., Masashi M., Xianmin G., et al. Different hepatitis B virus genotype distribution among asymptomatic carriers and patients with liver diseases in Nanning, southern China. Hepatology Research 2002;22:37-44.

20. Tsuboda A., Arase Y., Ren F., et al. Genotype may correlate with liver carcinogenesis and tumor characteristics in cirrhotic patients infected with hepatitis B virus subtype adw. J Med Virol 2001; 65:257-65.

21. Valdes C.A., Buti M., Costa X., et al. The role of HBV genotype in the emergence of YMDD variants in chronic hepatitis B patients treated with lamivudine. J Hepatol 2003; Supp1 1, Abstract 613 